\title{
The Camouflage of "Tough Woman": The Resistance of Female Character Against Patriarchal Ideology in Mulan
}

\author{
Rahmadani Lailawati ${ }^{1}$, Qory Islami ${ }^{2}$, and Mutia Sari Nursafira ${ }^{3}$ \\ 1,2 Universitas Lancang Kuning, Pekanbaru, Indonesia \\ ${ }^{3}$ U-Raise Academy, Pekanbaru, Indonesia \\ ailha.rahmadani@gmail.com
}

\section{ARTICLE HISTORY \\ Received : 12 September 2020 \\ Revised : 23 September 2020 \\ Accepted : 27 September 2020}

\section{KEYWORDS}

Critical Discourse Analysis

Female Resistance

Patriarchal Ideology

\begin{abstract}
This present study exposes how the patriarchal ideology still survives in the international English movie depicting Chinese women, Mulan (1998) and Mulan (2020). This present study uses critical discourse analysis to analyse the movies, focusing on the the dialogue, characteristics and events in the movies. This study contributes by critically comparing how English movies which are directed and scripted by English native speakers depict the role of women in the patriarchal China. The results showed that despite the 22-year gap between movies, the portrayal of women becomes worse, presented differently due to a change in genre, and is only seemingly improved at the tail end of the latest movie. While there are differences in how both Mulans are faced with problems and how they face said problems, her resistance as female neither reflects nor felt by Chinese women.
\end{abstract}

\section{Introduction}

The perception of females in the eye of society is an interesting issue in Chinese context due to its history. China's one-child policy has been viewed as draconian for leading to gender-selective and forced abortion issues, but has also contributed to the balance in gender in current higher education because parents with female child had to invest in their child's future "despite" their sex (Feng et al., 2016). Despite the apparent improvement on education for females, women still face blatant discrimination in obtaining a place, let alone a desirable position, in the workplace (Dawson, 2019). Similar to other countries around the world, although females are being encouraged to try out male-dominant occupations on paper, males are not encouraged to do same on practice, thereby workplaces continue to show high preference for men on the basis that women cannot be depended on for their potential future as child-bearers (Gietel-Basten et al., 2019). Consequently, countries utilise the power of films to represent and empower females, and one of the most influential films that depicts the life of Chinese women is Mulan (1998).

Representation itself is interpreted as how the world is constructed socially and presented to people in specific meanings. Representation refers to all forms of media, especially mass media, to all aspects of reality or reality, such as society, objects, events, to cultural identity. Representation not only involves how cultural identity is presented, or instead constructed, in a text but is also constructed in the process of production and reception by people who consume the cultural values represented (Derin et al., 2020; Rahman, 2017). In films as cultural representations, films construct values absolute cultural values in themselves and how those values were produced and how they were consumed by the people who watched the film. So, there is a kind of process of exchanging cultural codes in the act of watching films as a cultural representation. The films' presentations are now considered the most influential media, which is one of the media that can have the power to influence society. Films can also provide fictitious stories or stories that are not necessarily true, which makes people's viewpoints the same as filmmakers. Through representation, something can be described as good or bad and influence the perspectives of people who consumes the works (Rahman, 2018). The case here is that incorrect or skewed representation is something that often happens in films.

Mulan (1998) has received critical praise for its depiction of the position and role of women in China. The movie contains scenes of the struggle born from how women in families and society in China has a different position from men. In Chinese society and family, men play an essential role as the one who can only hold full power in political leadership, moral authority, and social rights.

Chinese females must obey their fathers before marriage, obey their husbands as long as they marry, and obey their sons when they become a widow. Chinese women has been lacking agency in choosing who they marry as families continue to push them to find suitable husbands at a young age and they are not permitted to 
refuse the marriage arrangements made by their families. A daughter must obey her father's orders, including in marriage matters. Women are still expected to stay at home and take care of their families. These values have been introduced and reinforced to the people through the media, not just entertainment movies but also even in official textbooks and especially the societal attitudes (Norova, 2020). This system has intimidated Chinese women by the patriarchal culture since ancient times. The effects are still felt to date as many Chinese parents continue to prfer sons over daughters, and the worldwide Covid-19 pandemic's social distancing policy reveals that domestic abuse against females are still rampant.

These struggles are shown in Mulan (1998), but the animated movie tells the world that the protagonist and titular character can overcome such obstacles (Brocklebank, 2000). In the film, Mulan literally stepped into the shoes of an obviously male-exclusive duty, escaping punishment for it yet ending up receiving praise and bow from the Chinese Emperor and the entire Chinese society. The dramatic story of how this Chinese woman overcame the patriarchal ideology is highly jarring when compared to how real life Chinese women are still struggling against it, thus the movie continues to be held under the world's critical eye over the years (Yin, 2011; Cheu, 2013). With how internationally influential the movie has become, future adaptations are consequently burdened with the responsibility to address their predecessors' flaws and adapt to modern status quo as well as discourse (Anwar et al., 2019; Jung \& Kim, 2020). Therefore, Mulan (2020) is expected to better represent Chinese women and how they resist the existing patriarchal ideology, thus there is a need for a critical discourse analysis to understand, verify, and judge the media's representation (Jackson et al., 2016). The researchers are highly interested to analyse and compare both the predecessor and the successor because they are English language movies that hold the heavy burden of representing a sensitive and long-lasting culture of a discriminated race and gender to the entire world.

\section{Literature Review}

\subsection{Sex and Gender}

Sex and gender have different meanings, even though they discuss the same thing about men and women. According to Echols, John M. (1983:89), "Sex is the characteristic that distinguishes the male from the female" biological characteristics that distinguish between male and female sexes. According to Humm Maggie (2002:421-422), "Sex is a conceptual interpretation between sex and gender so that expectations of gender roles can be changed if they are considered not biology."Based on the experts' opinions above, it can be concluded that sex is the sex of men and women who have different characteristics, biologically or non-biologically.
Gender is the differentiation of roles, attributes, traits, attitudes, and behaviour that grow and develop in society. Furthermore, gender roles are divided into productive roles, reproductive roles, and social roles. The word gender can be interpreted as the role formed by society and behaviour that is embedded through socialization that is related to the sexes of women and men. There are biological differences between women and men - but culture interprets these biological differences into a set of social demands about the appropriateness in behaviour, and in turn, rights, resources, and power. Although these demands vary by community, there are some striking similarities. For example, almost all community groups hand over responsibility for child care to women, while military tasks are given to men.

\subsection{Gender Roles}

Gender role is a trait inherent in men or women who are socially and culturally constructed. For example, women are gentle, emotional, motherly, rational, strong, manly, and male mighty. Gender results of the construction of the culture, created by humans, whose nature is not fixed, which changes from time to time, can be transferred and exchanged menu time, place, and local culture of one sex to another sex.

According to Hess (1978:8), history of gender differences between men and women occurs through a process that is long, formed, socialized, and constructed socially and culturally through the teachings of religion and the State, so that gender differences are understood and considered as the nature of men and women. Furthermore, roles are oppressive for women. they believe that the female gender role was constructed instead of an ideal male role and helps perpetuate patriarchy.

\subsection{Patriarchy: Gender Injustice}

Patriarchal culture cannot be separated from women. The domination of men over women has become a social reality in various countries. According to Bressler (2007, p.159)," patriarchal culture is a system where women are considered as "property" and men as humans. In this case, men are the subject, and men can arrange women in social and cultural life. It makes the women try to fight for their degrees and rights and free them from the patriarchal culture". The patriarchal culture will continue as long as society continues to construct status and role itself. As an analysis of a song, I Have a Heart, in the song, the poem illustrates that women are weak in every verse of the song. How can they not be, they are left silent, hurt he was silent because women have hearts so that it is reflected in the community's minds, especially adolescents currently implementing that women use feelings. In contrast, men use logic and continue so that movements to raise the degree of women will be displaced if the use of things "In" to indoctrinate the community again. Even young children have been viewed through several Disney films, which illustrate that women are weak, women sell their bodies for the benefit, and even women have no stance. 
Gender injustice is a difference in treatment based on gender reasons, such as restrictions on roles, exclusion or favouritism, which results in violations of the recognition of human rights, equality of rights between men and women as well as fundamental rights in the social, political, economic, cultural, and others.

\subsection{Female Resistance}

Women's Resistance across cultural and geographical boundaries, leaning toward narratives and stories written by women's voices, is usually not heard in the mainstream in everyday life. Women's Resistance in all matters proves the woman's act of defending her life in all the problems she is facing and strengthening women, so they do not look weak with men's actions or power.

\section{Method}

This present study uses critical discourse analysis to compare the representation of female resistance in Mulan (1998) and Mulan (2020). Critical discourse analysis unmasks ideologies embedded within a media to unravel insidious covert messages (Fairclough, 2013; Sahmeni \& Afifah, 2019).

The researchers analyse the dialogues, characters and events of both movies to show how Chinese women are depicted within foreign movies.The researchers provided data from the movies' scripts. The data serves as evidence of how these worldwide influential movies narrate female. The researchers identified and explained the gender-related injustice faced by women in the movies, comparing how both foreign English movies handle this long-standing and deep-seated cultural issue.

\section{Results \& Discussion}

Mulan (1998) is an animated Disney film directed by Tony Bancroft and Barry Cook. Mulan (2020) is the live action adaptation directed by Niki Cole. Both movies told the story starts with a young woman named Mulan struggling to stick to her role as a potential bride, who impersonated the Chinese army as a man, exiled by her commander once the truth comes out, and later accepted by the entire kingdom after saving the emperor. Unlike previous Disney live action remakes that sticks close to the original animated movies, the director of Mulan (2020) takes many creative liberties to make the movie lean towards the "wuxia" (meaning: martial heroes) genre.

\subsection{How Women are Introduced}

The setting of both films takes place in China during the $20^{\text {th }}$ century dynasty kingdom era. In the original animation, Mulan's first appearance is her listing off several qualities that a desirable woman must possess, which are "quiet and demure ... graceful, polite, delicate, refined, poised ... punctual!" [OA-FM.1]. Within the first musical where Mulan is forced to be washed and polished, the role of women is establsihed together with the role of men in the line, "We all must serve our Emperor who guards us from the Huns; a man by bearing arms; a girl by bearing sons," [OA.FP.1] The movie shows the audience that Mulan is devastated by the fact that she could not be the perfect daughter and the perfect bride despite her hard work and thus, could not bring honour to her family as the sole daughter.

In the live action, Mulan is shown to practice martial arts at a young age, introducing the genre as an epic martial arts movie rather than the original's children adventure movie. Mulan is deliberately shown as a reckless troublemaker who, despite showing impressive talent, is disliked by her village barring her father. Her role as a female is first stated by her mother who was scolding her father for letting her train, "You forget that she is a girl, not a boy. Girls bring honour through marriage [...] What man would marry a girl running around rooftops, chasing chickens?" [LA-HL.3]. Moreover, in the 2020 adaptation, Mulan is not the sole daughter and has a younger sister, who is portrayed as the perfect daughter according to their mother, who says "Xiu gives me no trouble. The matchmaker will find a good husband for her," [LA-HL.7]. The belief that females can only bring honour to their family by marrying is shown to be planted in young Mulan, thus when she became an adult and is suddenly told that the village's matchmaker has found her a potential husband, she only responded with a soft affirmation despite her obvious reluctance.

Both movies conveyed the status quo of how Chinese society expects from women. Women are taught by their family and society that the only way they can contribute to their family is by growing up to be a desirable bride. Feelings of love and familiarity with the potential partner seem to not be given any consideration because women are actively placed into reproductive roles from the start. Limbach (2013, p.176) pointed out how "Mulan (and, by extension, all other girls), must submit to a feminizing process." The society in Mulan (1998) and the parents in Mulan (2020) must actively intervene and change Mulan to possess certain qualities lest she will not become a bride and thus, somehow, a failure of a woman.

\subsection{Gender Injustice}

The intensity of the perfect female "Honor to Us All" narrative is matched by the perfect male "I'll Make a Man Out of You" narrative. Much like how women must actively perform certain qualities that the matchmaker dictates, men must also actively perform certain qualities that the army commander demands. Mulan (2020) continues to impress that the goal for females is to be a bride, and the goal for males is to be a soldier, as testified by how Mulan's old and sickly father readily accepts the fact that he will die in battle because "this is my job. This is how I bring honour to our family," [LA-HZ.49]. 
However, patriarchal ideology is transparent in both movies by the way men are always framed as who is desired, who is demanded, and who is dominant. The first is best represented by the animated movie's lyrical line "Did they send me daughters, when I asked for sons?" [OALS.39]. The second is best represented by the live action's characters. The third is best represented by the fact that women are taught to give their bodies to men, while men are not expected to devote or sacrifice for women specifically, but for their country as a whole.

While the movie shares a lengthy list of clear-cut adjectives that a woman must become, the qualities demanded upon a man is startlingly vague, as sung in the lines "swift as a coursing river [...] force of a great typhoon [...] strength of a raging fire, mysterious as the dark side of the moon," [OA-MP.57]. The process to become a man lacks the methodical procedure that females undergo, such as shown in the clean-up and make-up scenes.

In this film, men's dominance of power is apparent, especially in leadership held by men, freedom of speech or speech of men is more dominant than women in the film Mulan. Chi Fu was ordered by the emperor to tell the whole province to recruit a man as a soldier to help the Chinese troops. Then Chi fu went to each province to tell each family that there must be one man representing his family as warriors against the nation; only men can take part in the training. In the dialogue, it explained the dominance of women, that only men could join the war. In the film, there is a stereotype. The stereotype is assessing someone against someone who is done by perception or group thought that person is categorized. The professional dresser and Mulan's mother were singing while tying Mulan's waist to make it look small because in Chinese tradition if a woman has a small waist, she will give good offspring. The song explains that the stereotype of women who have a small waist will have good offspring.

In this film, there is Marginality, the process of neglect or marginalization of rights to sex, and so is experienced by some women who feel marginalized by men. Mulan tried to find someone who could trust him to let him know that the Huns were still alive, and he would return to attack the royal dynasty. However, in his efforts to convince the people or men he talked to, none listened to what Mulan said, including Mushu( little dragon messenger from the ancestors to help Mulan). He also ignored Mulan, telling her to"remember, you are a woman" [OA-MD.69], meaning that the position of women here is marginalized because if she becomes a woman, she speaks not heard by others. In this film, there is violence against women as civilization appears in many forms. Violence is an attack on a person's mental, physical, and psychological integrity. Violence is not only related to such as rape, beatings, and torture, but also non-physical traits such as sexual harassment. Perpetrators can be our own family or community.

\subsection{Female Resistance against Patriarchal Ideology}

The animated movie gives Mulan two choices after the battle, and these two choices are akin to a rock and a hard place. One is for her to work for the emperor, which she declines, and the other is for her to return to her role in society as a daughter and a bride, which she chooses. Although she is credited as a figure that defies the patriarchal ideology, the actualisation of the resistance is actually done by the male characters, where Mulan's male comrades dressed in drag and embraced femininity without shame to save the emperor, and where her father threw away the symbols of honour and declared that "the greatest gift and honour is having you as a daughter," [OA-FZ.94].

These two crucial moments that portrays men embracing women's qualities and ending the blatant preference for sons are, regrettably, completely absent in the live action. The crucial difference that makes Mulan (2020) a disappointing diverse representation movie is how it does not challenge the patriarchy, but rather enforces it even worse. Rather than starting from scratch like all men and eventually growing strong as a soldier like in the animated movie, the live action Mulan's character as a prodigious warrior from birth alienates her from the majority, if not all, of Chinese audience. Akin to nail in a coffin, the adaptation tells the audience that even when a female is as powerful as Mulan, she is still submissive and must serve the men because, as Mulan told the female witch antagonist, "I know my place [...] to serve the Emperor," [LA-HM.207].

\section{Conclusion}

This critical discourse analysis reveals that the latest disneyfication of a female heroine continues to fail in empowering women, and worsens the representation of Chinese people. In the animated movie, Mulan eventually returns to her role as the daughter and bride. In the live action remake, Mulan does the same and is hinted to accept a decorated position in the Chinese army. The role of women is very blatantly dictated and reflected in both movies' introductions, but the actual resistance and defiance of the patriarchal ideology is deleted and camouflaged behind the façade of "powerful and prodigious Mulan" in the 2020 adaptation. The representation of Chinese values and female empowerment offered in the new Disney big theatre movie is superficial at best, going down the drain rather than breaking the ceiling.

\section{Acknowledgement}

The completion of this research study could not have been accomplished without the support of the UnilakResearch Advancement for Intellectual and Scientific Empowerment (U-Raise) Academy. 


\section{References}

Anwar, Laraswati, A., \& , R. (2020). Critical Discourse Analysis in Media Studies: A Review Research on Its Application in Indonesian Context. Elsya : Journal of English Language Studies, 2(1), 32-36. https://doi.org/10.31849/elsya.v2i1.3615

Brocklebank, L. (2000). Disney's" Mulan"-the" True" Deconstructed Heroine?. Marvels \& Tales, 268-283.

Cheu, J. (Ed.). (2013). Diversity in Disney films: Critical Essays on race, ethnicity, gender, sexuality and disability. McFarland.

Dawson, K. (2019, 29 September). China women still battling tradition, 70 years after revolution. Aljazeera.

https://www.aljazeera.com/news/2019/09/29/chinawomen-still-battling-tradition-70-years-afterrevolution/?gb=true

Derin, T., Susilo Putri, N., Nursafira, M. S., \& Hamuddin, B. (2020). Discourse Analysis (DA) in the Context of English as a Foreign Language (EFL): A Chronological Review . Elsya : Journal of English Language Studies, 2(1), 1-8. https://doi.org/10.31849/elsya.v2i1.3611

Fairclough, N. (2013). Critical discourse analysis: The critical study of language. Routledge.

Feng, W., Gu, B., \& Cai, Y. (2016). The end of China's one-child policy. Studies in family planning, 47(1), 83-86.

Gietel-Basten, S., Han, X., \& Cheng, Y. (2019). Assessing the impact of the "one-child policy" in China: A synthetic control approach. PloS one, 14(11), e0220170.

Hess. T. (2008). Gender Role. Green Wood Press.

Jackson, T., Jiang, C., \& Chen, H. (2016). Associations between Chinese/Asian versus Western mass media influences and body image disturbances of young Chinese women. Body image, 17, 175-183.

Jung, Y. S., \& Kim, E. J. (2020). Analysis of Gender Role Behaviors in Accordance with Visual Expression of Disney Animation: Focusing on Female Characters of Mulan, Tangled, Moana, and Frozen 2. The Journal of the Korea Contents Association, 20(7), 107-117.

Limbach, G. (2013). "You the Man, Well, Sorta": Gender Binaries and Liminality in Mulan. Diversity in Disney films: Critical essays on race, ethnicity, gender, sexuality and disability, 115-128.

Norova, N. (2020). Sexism in Elementary EFL Textbooks: Spotted in Uzbekistan . REiLA : Journal of Research and Innovation in Language, 2(2), 37-45. https://doi.org/10.31849/reila.v2i2.4470
Rahman, F. (2017). The revival of local fairy tales for children education. Theory and Practice in Language Studies, 7(5), 336-344.

Rahman, F. (2018). The Constraints of Foreign Learners in Reading English Literary Works: A Case Study at Hasanuddin University. Journal of Arts and Humanities, 7(2), 01-12.

Sahmeni, E., \& Afifah, N. (2019). Using Critical Discourse Analysis (CDA) in Media Discourse Studies: Unmask the Mass Media. REiLA : Journal of Research and Innovation in Language, 1(2), 39-45. https://doi.org/10.31849/reila.v1i2.2764

Yin, J. (2011). Popular culture and public imaginary: Disney vs. Chinese stories of Mulan. Javnost-The Public, 18(1), 53-74. 